\title{
Examining conceptualizations of communication
}

\author{
Michael Haugh and Anthony J. Liddicoat \\ Griffith University and University of South Australia
}

\section{Communication and linguistics}

Language is a fundamental part of human communication systems and linguistics, as the study of human language, is ultimately concerned with questions of communication. The extent to which communication is given explicit attention in linguistics, however, varies according to the theoretical and heuristic orientations of linguists. While linguists focusing on the use of language tend to emphasize the importance of communication, those with a generativist theoretical or descriptivist orientation often have a much more ambivalent stance. Yet while the conceptualization of communication may seem of peripheral interest to many linguists, it can be argued that communication is at least implicit in most, if not all, theories of linguistics. In particular, communication has often been taken as a definitional criterion for understanding exactly what language is and therefore for constructing what it is that linguists study. Yet despite its (tacit) importance, linguistics has not really considered what is meant by the term communication and how theories of communication influence how the discipline is understood and practised.

The focus in linguistics on communication as a central element for understanding language grew out of the work of the Geneva School Structuralist, most notably Saussure (1916). For Saussure, language was the science of speech communication. Communication itself was in fact rather a simple process in which an active speaker encodes a message for a passive listener- an unproblematic exchange of meaning through language. Communication as a process is located fundamentally within the speaker and is essentially individual, in fact, for Saussure, parole is defined as "un acte individuelle de volonté et d'intelligence" [an individual act of will and intellect] and the act of communication consists of combinations of the language code to express the speaker's thought and a psycho-physical mechanism by which these combinations are produced. Saussure's interest in language was based on the properties of language which allowed meanings to be communicated, and it was this focus on language as communicative which distinguished Geneva School linguistics from the comparative grammarians of earlier generations for whom language was studied essentially as forms. While a sense of language as communication may have been a starting point for the Geneva School structuralists, their focus on the nature of the language faculty separated language as an object of academic study from particular instances of language used to communicate. ${ }^{1}$ For Saussure (1916), speech communication was something located in the mind, or more precisely within the collective mind, of a community of idealised speakers.

Harris (1981, 1997, 2003) has long argued that Saussure's conceptualisation of language as the science of speech communication relies on untenable assumptions about communication itself (see also Graddol 1994). In particular, he claims that Saussure adopted a "telementation" model of communication, a "theory which explains communication as the transference of thoughts from one person's mind to another person's mind” (Harris 2003: 25), and, more controversially, that mainstream linguistics is implicitly committed to such a model. Yet while the view that communication involves the transfer of thoughts and feelings through language is strongly embedded in common sense ways of talking about language and

\footnotetext{
${ }^{1}$ This is summarised by Saussure’s (1916) statement "la linguistique a pour unique et véritable objet la langue envisagée en elle-même et pour elle-même” [linguistics has as it sole, true object language viewed in itself and for own sake], an idea which was taken from Bopp (1816).
} 
communication (Krippendorff 1993; Peters 1989; Reddy 1993), it is less apparent that all linguists actually subscribe to such a model (Borsley 1997; Borsley and Newmeyer 1997; Joseph 1997; Mann 2001). Nevertheless, Harris raises an important question that still has resonance, namely, is communication under-theorized in linguistics?

Harris (2003) also argues that Saussure's conceptualisation of language as the science of speech communication involves a problematic abstraction which separates language out from the rest of human communication and in so doing constitutes language as an abstract phenomenon as linguistic communication. In so doing Saussure developed an ambiguous conceptualisation of speech communication, which potentially meant communication by verbal utterances as distinct from other ways of communicating, but was much more restricted in its academic focus to the investigation of an idealised capacity for communication using speech.

Jakobson (1961), like Saussure, views the focus of linguistics as the "domain of verbal communication”, however, he notes that linguistics is frequently concerned only with part of human verbal communication:

it is still frequently overlooked that the finite ensemble of "standard representations" is limited to lexical symbols, their grammatical and phonological constitution, and to the grammatical and phonological rules for combination. (Jakobson 1961: 247)

He argues that language is a fundamental tool of communication and that it is shared use of a language which makes communication possible and locates communication as the real site in which language exists: "The constituents of the code, for instance, the distinctive features, literally occur and really function in speech communication” (Jakobson 1961: 248). For Jakobson, the study of communication holds out the possibility for linguistics to expand its conceptualisation of the scope of what linguistic analysis needs to address. Although Jakobsen sees communication as more than a definitional starting point for linguistics and argues for an interaction between understandings of language and of communication, he does not develop or express a theory of communication in constructing his argument. Jakobsen, appears to understand communication more as a self-evident incidence of the deployment of language, which can serve as a "reality check" for linguists, rather than as a theorised and theorisable domain for investigation using linguistics.

That the nature of the association between language and communication in linguistics is problematic became a focus of debate in formal approaches to linguistics in an exchange between Jackendorff and Pinker (Jackendorff and Pinker 2005; Pinker and Jackendorff 2005), on the one hand, and Chomksy, Hauser and Fitch (Fitch, Hauser and Chomsky 2005; Hauser, Chomsky and Fitch 2002) on the other. The argument centred on the relationship between language and communication and whether the language faculty was purely for communication or had other biological purposes.

In their discussion, Hauser et al. argue that the focus of language, and hence of linguistic analysis is on computational operations for mapping lexicon and syntax and manipulating syntactic structures:

Roughly speaking, we can think of a particular human language as consisting of words and computational procedures ("rules") for constructing expressions from them. (Hauser et al. 2002: 1576)

Language in this sense is not just the study of human speech communication as it was for Saussure and Jacobson, but rather the study of the computational system which is used for 
performing speech communication, although they acknowledge communication as being one of the things that language is used for:

humans use language in just about every social interaction, including courtship and mating, aggressive interactions with competitors, caring for offspring, sharing information with kin, etc. Thus there can be little doubt that language is useful for communication with other humans, and communication must be one of the primary selective forces that influenced the evolution of FLB [Faculty of Language in the broad sense]. (Fitch et al. 2005: 186)

This argument relies on earlier arguments made by Chomsky (1975: 56-57, 1980: 230, 2000: 75) against the idea of language as a system of human communication but rather a system for expressing thought, which is only incidentally used for communication. Chomsky in a recent interview reiterates his view:

the general fact about language, which is not really in doubt, is that primarily we use it for thought. Secondarily, we use it for interaction with others. And a pretty small part of that interaction with others is communication in any independent sense of the term “communication”. (Andor 2004: 109)

Chomsky claims that such a position reflects "common sense”:

Statistically speaking, almost all use of language is internal dialogue. You can't go for a minute without talking to yourself. It's almost impossible. It takes a tremendous act of will not to talk to yourself. Is that communication? Certainly not-it's thought. So at least statistically speaking, language is almost entirely non-communicative. (ibid.: 108)

The problem with such appeals to common sense, however, is that they can easily be countered by further appeals to common sense. For instance, if language is used primarily for thought, why is it that we cannot acquire languages simply by thinking about them? It is also worth noting that Chomsky is making an anecdotal appeal to intuition here without any actual statistical survey of language use being undertaken. Such arguments only go to show how common sense views can unduly constrain our approach(es) to the study of language.

Pinker and Jackendorff, in contrast, reject the idea that language is not primarily a form of human communication and argue rather that language is only adequately to be understood from the perspective of communication.

Indeed, if language were not designed for communication, the key tenet of Minimalism that language consists of a mapping from meaning to sound - would not be a "virtual conceptual necessity," as Chomsky has repeatedly asserted, but an inexplicable coincidence. The only way to make sense of the fact that humans are equipped with a way to map between meaning and vocally produced sound is that it allows one person to get a meaning into a second person's head by making a sound with his or her vocal tract (Pinker and Jackendorff 2005: 225).

For Pinker and Jackendorff, the distinction between communication and expressing thought is problematic - for them, thought is expressed primarily for the purpose of communicating the thought to others.

The problem here is not so much a disagreement about whether language is or is not used for communication, but rather about the nature of communication. For Chomsky and his 
colleagues, expressing thoughts is not inherently communicative, whereas for Pinker and Jackendorff it is. In each case, the writers argue for or against an idea of language as communication, and assert that particular human activities are or are not communicative, but without attending to what they actually mean by the term communication. In this exchange, communication is a core underlying concept, but it is not a theorised concept. Linguists' theories of communication are often borrowed, consciously or unconsciously, from other disciplines or from general understandings of the term with little consideration of how the theories adopted integrate with or impact on theories of language and the practice of linguistic research. Yet without a careful consideration of the underlying epistemological and ontological commitments of such theories, various theoretical approaches may ultimately be incommensurable as "a finding in one cannot be seen as a finding in another" (Mann 2001: 4). In this volume we thus explore the conceptualizations of communication in a range of different linguistic sub-disciplines.

\section{Overview of the volume}

The volume opens with a paper by Cliff Goddard analysing the meaning of communication and language in everyday English using the tools of the Natural Semantic Metalanguage. A number of semantic explications are given for these two concepts, and epistemological assumptions underlying these notions are teased out. Goddard then argues that the everyday notion of communication privileges information transfer as the paradigm case of human interaction, a view that can be traced back to John Locke's (1690) influential Essay Concerning Human Understanding (Peters 1989). The notion of language, on the other hand, is found to be essentialist in that it links different ways of speaking with supposedly different "kinds of people" in different places. The limitations of English folk metalanguage for talking about language and communication thus become apparent.

A discussion of the ways in communication is conceptualized in introductory linguistics follows in Timothy Jowan Curnow's paper. After carefully analysing how communication is defined in a number of introductory textbooks, Curnow suggests that communication in linguistics is generally conceptualized as the use of signs to get someone to know something. The latter element reflects the common sense view of communication as the transfer of information, which was first popularized in academic discourse following the work of Shannon and Weaver (1949). Curnow draws attention to the contradiction between what linguists know about communication (that is, it is not simply transfer of information) and what they say about communication (at least to first year linguistics students). He argues this stems from the conceptualisation of language by many linguists as a purely cognitive system, as well as the problems for delimiting the proper focus of study of linguistics that arise when trying to define linguistics in relation to communication. He concludes that while the transfer of information model is inadequate as a model of communication, it serves a useful purpose for linguists, namely, defining disciplinary boundaries.

The different ways in which communication is conceptualised by linguists in the field of second language acquisition (SLA) is next discussed by Susana Eisenchlas. In her paper, Eisenchlas teases out both explicit and implicit understandings of communication in SLA. She finds a great deal of heterogeneity in perspectives amongst SLA researchers, in contrast to the fairly widespread reliance on the transfer of information model in descriptive linguistics. Three broad perspectives on communication are outlined in her paper: a psycholinguistic perspective which relies on cognitively-grounded transfer of information model, a language use perspective where communication is conceptualized as a social product of interaction that is negotiated and co-created by participants, and a societal perspective where the conceptualization of communication is grounded in broader social 
issues such as power and identity. Eisenchlas points out each perspective has its own limitations, and crucially that these different perspectives stem from the researcher's perceived scope of the discipline of SLA.

This last theme is further developed in Judy Gould's paper on the conceptualization of communication in the field of speech pathology. She argues that the preferred notion is closely related to what is perceived as effective communication by speech pathologists, that is, producing and understanding speech appropriate to one's age. Gould points out that this biological grounding of communication is essentially cognitivist, and so not surprisingly the transfer of information model of communication predominates in the field. She argues, however, that this conceptualization of communication as biological is too narrow to deal with the issues that arise in the practice of speech pathology across different cultural and political contexts. The paper concludes with Gould pointing out the potential speech pathologists have in regards to making a greater contribution towards our understanding of communication.

While the conceptualization of communication as primarily a phenomenon embedded in the minds of individuals predominates in the guise of variations in the transfer of information model across a number of fields in linguistics, the next three papers offer arguments for a shift in the way in which we frame communication, from being simply a cognitive phenomenon to a more interactionally-grounded perspective. Maurice Nevile and Johanna Rendle-Short consider the way in which communication is conceptualized in conversation analysis (CA), where the focus is on the understandings of participants that emerge through the sequential development of interaction. Through an analysis of micro-detailed transcriptions of naturally occurring data, in this case an unsuccessful proposal for a visit, Nevile and Rendle-Short illustrate how CA conceptualizes communication as social interaction that is jointly accomplished by participants. They demonstrate how communication in naturally occurring interaction goes beyond the transfer of information to being a means of accomplishing actions for particular social ends and with real social consequences. The limitations of the transfer of information model are also apparent in the way in which participants interpret and act upon one another's contributions, thereby contributing towards the contingencies of the moment which in turn participants design and coordinate their own speaking turns to meet.

The implications of re-conceptualizing communication as an interactional achievement for how we conceptualize intentions and cognition are next considered in Michael Haugh's paper. After briefly reviewing how conceptualizations of communication in pragmatics are more often than not explicitly linked to the intentions of the speaker, Haugh argues that locating the inferential work required to work out these intentions solely in the minds of individual hearers lacks the explanatory power required to account for pragmatic phenomena, due to the inherent ambiguity in the temporal, onotological, and epistemological status of such intentions. The notion of "dyadic cognizing", where inferential work is conceptualised as being contingent on both what precedes (anticipatory inferencing) and follows (retroactive inferencing) in interaction, and thus as inherently non-summative and interdependent, is introduced. It is then proposed that the conceptualization of communication in pragmatics move away from its current a over-reliance on speaker intentions to the broader notion of intentionality.

The focus next shifts to the interaction of language, culture and communication in Anthony Liddicoat's paper on the conceptualization of communication from the perspective of intercultural communication. Liddicoat argues that culture impacts on communication at a number of different levels. First, culture constitutes an important aspect of the context in which communication occurs, influencing the ways in which utterances are designed and interpreted. Second, culture may also influence the structure of texts in the form of different 
genres or text types that are implicitly accepted as appropriate within different cultural settings. The influence of culture is also apparent in the different pragmatic and interactional norms that emerge when examining speech acts across different cultures. Finally, Liddicoat argues that culture can impact upon linguistic form at the morphosyntactic and semantic levels. He claims that communication is therefore the use of a culturally shaped code in a cultural context to create and interpret culturally shaped meanings.

This volume concludes with an in-depth consideration of how we might better communicate about communication across disciplines by Helen Fraser and Andrea Schalley. Their paper draws not only from the contributions to this volume, but also other papers that were presented at the HCSNet Workshop on Conceptualising Communication (University of New England, 4-5 December 2005). In surveying a diverse range of perspectives on communication from linguistics and speech technology through to dance and music, their aim is not to find the "best" model of communication, but rather to make often assumed or implicit understandings of communication more explicit, thereby allowing points of difference and disagreement to be better understood. The paper also lays out a useful map or framework for examining the various positions that can be taken in relation to the nature and study of communication across disciplines. It is written in the spirit of encouraging further discussion rather than constraining or pigeonholing particular disciplinary perspectives. And it is in this spirit that this volume as a whole is offered.

\section{Final remarks: a communicative turn in linguistics?}

While intellectual life in the humanities and social sciences in the $20^{\text {th }}$ century was arguably dominated by the linguistic turn (Rorty 1967), what appears to be emerging at the beginning of the $21^{\text {st }}$ century is a so-called “communication turn” (Grant 2007: 10; Leydesdorff 2002). This volume is intended as a way to better understanding the implications of such a move for the discipline of linguistics. What emerges from the papers in this volume as a whole is that linguistics and its associated sub-disciplines make use of the concept of communication in a range of ways but without necessarily adequately theorising the concept. These papers also indicate that the under-theorised nature of the concept in linguistics has the potential to create problems, especially in those areas of linguistics which highlight the interpersonal nature of language.

The aim of this volume though has not been to necessarily advance one view of communication as being inherently superior to other views. Indeed, as Krippendorf warns:

privileging any one theory of communication as the general one, one that subsumes all others, without consent by those theorized therein is likely to lead to an intellectual imperialism of first-order understanding. (Krippendorf 1993: 16)

Nevertheless, it is also apparent that the common sense view of communication as the straightforward transfer of thoughts from one mind to another does not possess sufficient theoretical acumen to capture all the complexities of linguistic communication. Across many of the papers in this volume a move towards a more interactionally-grounded view of communication has emerged, where communication involves "participants' contingent, emergent and joint accomplishment” of meaning (Kasper 2006: 305). ${ }^{2}$ Such a move, however,

\footnotetext{
${ }^{2}$ It is worth noting that such conceptualizations do not necessarily entail an understanding of communication as being somehow inherently cooperative or as always meaning "agreement”. Communication often involves a degree of uncertainty (Grant 2007), and can involve diverging as well as converging understandings of what is being communicated (Arundale 1999; Haugh 2008a, 2008b).
} 
has implications for the study of language, since despite claims to the contrary, linguistics cannot be completely divorced from the broader study of communication. Recent work in phonology and phonetics (Coupler and Ford 2004), syntax and grammar (Ochs, Schegloff and Thompson 1996; Setling and Couper-Kuhlen 2001), for instance, illustrates how interactional approaches to the study of language in context might productively expand the discipline of linguistics. However, perhaps even more so is the potential for linguistics to contribute to our understanding of communication:

The disciplines that are labelled as "linguistics" are collectively perhaps the only ones of the "communication sciences" that have the wide array of conceptual power tools necessary to take on a detailed scientific account of human communication. If linguistics does not produce a strong and credible account, perhaps no other discipline will. (Mann 2001: 4)

We thus suggest that a communicative turn in linguistics not only entails careful examination of how findings from interactional studies of language in context might fruitfully inform how linguistics is practised, but also encompasses the potential for linguists to make a valuable contribution to developing an even more comprehensive theory of linguistic communication.

\section{Acknowledgments}

We would like to thank Helen Fraser, Andrea Schalley and Dorothea Cogill-Koez for organizing the HSCNet Workshop on Conceptualising Communication from which this volume arises.

\section{References}

Andor J 2004 'The master and his performance: an interview with Noam Chomsky' Intercultural Pragmatics 1: 93-111.

Arundale R 1999 'An alternative model and ideology of communication for an alternative to politeness theory' Pragmatics 9: 119-154.

Bopp F 1816 Über das Konjugationssystem der Sanskritsprache in Vergleichung mit jenem der griechischen, lateinischen, persischen und germanischen Sprache Frankfurt am Main: Andreaische Buchhandlung.

Borsley R \& F Newmeyer 1997 'The language muddle: Roy Harris and generative grammar' in G Wolf \& Nigel Love (eds) Linguistics Inside Out. Roy Harris and his Critics Amsterdam: John Benjamins. Pp. 42-64.

Chomsky N 1975 Reflections on Language New York: Pantheon Books.

Chomsky N 1980 Rules and Representations New York: Columbia University Press. Chomsky N 2000 On the Nature of Language New York: Cambridge University Press.

Couper-Kuhlen E \& CE Ford (eds) 2004 Sound Patterns in Interaction: Cross-linguistic Studies from Conversation Amsterdam: John Benjamins.

Fitch W, M Hauser \& N Chomsky 2005 'The evolution of the language faculty: clarifications and implications’ Cognition 97: 179-210.

Graddol D 1994 'Three models of language description’ in D Graddol \& O Boyd-Barrett (eds) Media Texts: Authors and Readers Clevedon: Multilingual Matters. Pp. 1-21.

Grant C 2007 Uncertainty and Communication Basingstoke, Hampshire: Palgrave Macmillan. Harris R 1981 The Language Myth London: Duckworth.

Harris R 1997 'From an integrational point of view' in G Wolf \& N Love (eds) Linguistics Inside Out. Roy Harris and his Critics Amsterdam: John Benjamins: 229-310.

Harris R 2003 ‘On redefining linguistics’ in H Davis \& T Taylor (eds) Rethinking Linguistics London: Routledge. Pp. 17-68. 
Haugh M 2008a 'Intention and diverging interpretings of implicature in the "uncovered meat” sermon' Intercultural Pragmatics 5: 201-229.

Haugh M 2008b 'The place of intention in the interactional achievement of implicature' in I Kecskes \& J Mey (eds) Intention, Common Ground and the Egocentric Speaker-Hearer Berlin: Mouton de Gruyter. Pp. 45-86.

Hauser M, N Chomsky \& W Fitch 2002 'The faculty of language: what is it, who has it, and how does it evolve?' Science and Education 298: 1569-1579.

Jackendorff R \& S Pinker 2005 'The nature of the language faculty and its implications for evolution of language (reply to Fitch, Hauser, and Chomsky)' Cognition 97: 211-225.

Jakobson R 1961 'Linguistics and communication theory' in Structure of Language and Its Mathematical Aspects: Proceedings of Symposia in Applied Mathematics, Providence, RI: American Mathematical Society. Pp. 245-254.

Joseph J 1997 'The “language myth” myth: or, Roy Harris's red herrings' in G Wolf \& N Love (eds) Linguistics Inside Out. Roy Harris and his Critics Amsterdam: John Benjamins. Pp. 9-41.

Kasper G 2006 'Speech acts in interaction: towards discursive pragmatics' in K BardoviHarlig, C Félix-Brasdefer \& A Omar (eds) Pragmatics and Language Learning Volume 11 Honolulu: National Foreign Language Resource Center, University of Hawai'i at Manoa. Pp. 281-314.

Krippendorf K 1993 'Major metaphors of communication and some constructivist reflections on their use' Cybernetics and Human Knowing 2: 3-25.

Leydesdorff L 2002 'The communication turn in the theory of social systems' Systems Research and Behavioural Science 19: 129-136.

Mann W 2001 'What is communication? - a survey' Paper presented at BI-DIALOG 2001. Fifth Workshop on the Semantics and Pragmatics of Dialogue, Bielefeld University, Germany.

Ochs E, E Schegloff \& S Thompson (eds) 1996 Interaction and Grammar Cambridge: Cambridge University Press.

Peters, J 1989. 'John Locke, the individual, and the origin of communication' Quarterly Journal of Speech 75: 387-399.

Pinker S \& R Jackendorff 2005 'The faculty of language: What's special about it?' Cognition 95: 201-236.

Reddy M 1993 'The conduit metaphor: A case of frame conflict in our language about language' in A Ortony (ed) Metaphor and Thought Cambridge: Cambridge University Press. Pp. 164-201.

Rorty R 1967 The Linguistic Turn Chicago: University of Chicago Press.

Saussure F 1916. Cours de Linguistique Générale. Paris: Payot.

Selting M \& E Couper-Kuhlen (eds) 2001 Studies in Interactional Linguistics Amsterdam: John Benjamins.

Shannon C \& W Weaver 1949 A Mathematical Model of Communication Urbana, IL: University of Illinois Press. 